\title{
- Acidentes botrópicos de interesse em animais domésticos
}

\section{- Bothrops snake accidents of interest in domestic animals}

*Faculdade de Medicina Veterinária Zootecnia - Unesp Departamento de Clínica Veterinária Rubiāo Jr. s/n으 CEP: 18618-000, Botucatu, SP. End. Eletrôn.: joandes@ieg.com.br

\author{
* Joandes Henrique Fonteque ${ }^{1}$ - CRMV-PR- $n^{0} 3722$ \\ Ivan Roque de Barros Filho ${ }^{2}$ - CRMV-PR - $\mathrm{n}^{\circ} 3681$ \\ Michiko Sakate ${ }^{3}$ - CRMV-SP- no 2851
}

1 Pós-Graduando nível Mestrado do Departamento de Clínica Veterinária - FMVZ - UNESP/Botucatu/SP.

2 Pós-Graduando nível Doutorado do Departamento de Clínica Veterinária - FMVZ - UNESP/Botucatu/SP.

3 Professora Assistente Doutora do Departamento de Clínica Veterinária - FMVZ - UNESP/Botucatu/SP.

\section{RESUMO}

Apresentam-se, neste artigo de revisão, informações sobre os acidentes botrópicos em animais domésticos. Descrevem-se as principais espécies do gênero Bothrops, a sensibilidade dos animais ao veneno, a patogenia, os sinais clínicos, as seqüelas e complicações, os achados laboratoriais e de necropsia, bem como, o diagnóstico, tratamento e reações à soroterapia.

Palavras-chave: Bothrops, animais peçonhentos, acidente botrópico, animais domésticos.

\section{Introdução}

$\underline{0}$ envenenamento causado por serpentes constituise em problema importante nas Medicinas Veterinária e Humana nos países tropicais, devido a sua alta incidência, gravidade e seqüelas (SCARBI $e t$ al., 1995; BERROCAL et al., 1998). As serpentes venenosas brasileiras estão divididas em duas famílias e seis gêneros: família Viperidae constituída pelos gêneros Bothrops, Bothriopsis, Porthidium, Crotalus e Lachesis e a família Elapidae pelo gênero Micrurus ( FRANCISCO, 1997; MÉNDEZ, 1998).

$\mathrm{O}$ gênero Bothrops inclui animais que se caracterizam por serem solenóglifos, ovovivíparos e muito agressivos. Esse gênero é composto por mais de 30 espécies de serpentes que apresentam desenhos e cores diferentes, variando desde o verde até o negro. Os hábitos variam de acordo com a espécie e a idade, podendo ser encontradas sobre as árvores, enterradas, entocadas, à bei- ra de rios ou dentro d'água; podem alimentar-se de pequenos roedores ou pássaros. As serpentes adultas variam de $0,4 \mathrm{~m}$ até $2,0 \mathrm{~m}$ de comprimento e podem ser encontradas em todo o território nacional (ALVES et al., 1989). As principais espécies do gênero Bothrops estão representadas no Quadro 1, de acordo com seus nomes populares e distribuição geográfica.

As serpentes do gênero Bothrops são responsáveis por cerca de $90 \%$ dos casos de acidentes ofídicos em seres humanos na América do Sul e cerca de $89 \%$ dos casos no Brasil (DOURADO et al., 1988; KOUYOUMDJIAN, et al., 1990; SORENSEN, 1990; BARRAVIERA; PEREIRA, 1991; MENDEZ; RIET-CORREA, 1995), sendo que o Crotalus representa 8 a $15 \%$ (RIBEIRO, 1991; SCARBI et al., 1995).

Os dados epidemiológicos dos acidentes botrópicos de algumas regiões do Brasil estão relativamente bem determinados em Medicina Humana. Desde 1986, quando a notificação dos envenenamentos ofídicos passou a 


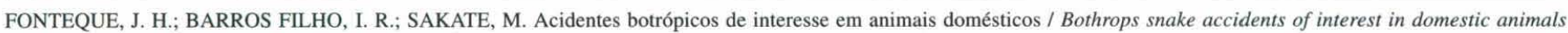
/ Rev. educ. contin. CRMV-SP / Continuous Education Journal CRMV-SP, São Paulo, volume 4, fascículo 3, p. 102 - 111 , 2001.

Quadro 1. Principais espécies, nomes populares e distribuição geográfica de serpentes do gênero Bothrops (B) no Brasil (Figuras 1, 2, 3, 4, 5 e 6).

\begin{tabular}{|c|c|c|}
\hline ESPÉCIE & NOMES POPULARES & ESTADOS DE OCORRÊNCIA \\
\hline B. alternatus & $\begin{array}{l}\text { Urutu, boicoatiara, boicotira, cruzeiro, coatiara, cotiara, } \\
\text { jararaca-rabo de porco e jararaca agosto. }\end{array}$ & MG, SP, GO, MS, PR, SC, RS. \\
\hline B. atrox & $\begin{array}{l}\text { Caissaca, combóia, cumbóia, jararaca, jararaca do norte, } \\
\text { jararaca do rabo branco e jararaca grão de arroz. }\end{array}$ & AM, PA, MA e RO. \\
\hline B. brazilis & Jararaca vermelha, jararacuçu e surucucu vermelha (falsa) & AM, PA e MT \\
\hline B. castelnaudi & Jararaca-cinza. & AM, GO e MT. \\
\hline B. cotiara & $\begin{array}{l}\text { Boicoatiara, boicotiara, coatiara, cotiara, } \\
\text { jararaca-barriga-preta e jararaca-preta. }\end{array}$ & SP, SC, PR, RS e RJ. \\
\hline B. erythromelas & Jararaca, jararaca-da-seca e jararacuçu. & Região Nordeste. \\
\hline B. fonsecai & Cotiara e jararaca. & SP, RJ e MG. \\
\hline B. igleasi & Jararaquinha. & $\mathrm{Pl}$. \\
\hline B. insularis & Jararaca-ilhoa. & Ilha da Queimada Grande-SP. \\
\hline B. itapetiningae & $\begin{array}{l}\text { Cotiarinha, boipeva, furta-cor, } \\
\text { jararaca-do-campo e pequena cotiara. }\end{array}$ & SP, MG, GO, PR, MS e SC. \\
\hline B. jararaca & $\begin{array}{l}\text { Jararaca, jaracá, jararaca-da-mata-virgem, } \\
\text { jararaca-do-campo, dormideira e jararaca-preguiçosa. }\end{array}$ & $\begin{array}{l}\text { Da Bahia até o } \\
\text { Rio Grande do Sul. }\end{array}$ \\
\hline B. jararacussu & $\begin{array}{l}\text { Jararacuçu, jararacuçu verdadeira, jararacuçu cabeça de } \\
\text { sapo, patrona, jararacuçu-tapete, surucucu, } \\
\text { urutu-dourado, urutu-preta e urutu-estrela. }\end{array}$ & SP e MG. \\
\hline B. leucurus & Jararaca. & BA-Salvador. \\
\hline B. marajoensis & Jararaca & AP, PA e llha do Marajó. \\
\hline B. microphthalmus & Jararaca. & Amazônia. \\
\hline B. moojeni & Caiçaca. & PI, PR, SP, MT, MS, MG, GO e MA. \\
\hline B. neuwiedi & $\begin{array}{l}\text { Boca de sapo, bocuda, jararaca, jararaca-cruzeira, } \\
\text { jararaca pintada, jararaca-do-rabo branco, } \\
\text { jararaquinha, rabo de osso e tira-peia }\end{array}$ & $\begin{array}{l}\text { Regiōes Centro-oeste, } \\
\text { nordeste, sudeste e sul. }\end{array}$ \\
\hline B. pirajai & Jararacuçu. & BA e MG. \\
\hline B. pradoi & Jararaca e preguiçosa. & BA e ES. \\
\hline
\end{tabular}

Fontes: FONSECA, 1949; HOGE; BELLUOMINI, 1960-62; HOGE; ROMANO-HOGE, 1978-79; AMARAL, 1978; BÜCHERL, 1979 ; CAMPBELL; LAMAR, 1989.

ser obrigatória, pasou-se a ter uma idéia mais acurada do número de acidentes botrópicos no País. Dos 20.000 casos nacionais, registrados por ano, 2.000 ocorreram no Estado de São Paulo (SCARBI et al., 1995). Na região de Botucatu/SP, localizada no centro do Estado, $80 \%$ dos acidentes botrópicos são causados pelas espécies $B$. jararaca, B. alternatus e B. neuwiedii e $20 \%$ por Crotalus durissus terrificus (BARRAVIERA et al., 1989).

Em relação aos animais domésticos, os estudos epidemiológicos são escassos e, segundo BICUDO (1994), em Botucatu/SP, dos 149 acidentes ofídicos registrados entre 1972 e 1989, 128 foram causados por serpentes do gênero Bothrops. No Estado do Rio Grande do Sul a maioria dos casos ocorre durante as estações de primavera e verão (meses de outubro a março) (MÉNDEZ; RIET-CORREA, 1995) e envolve as serpentes dos gêneros Bothrops e Crotalus (GRUNERT; GRUNERT, 1969).

\section{Sensibilidade ao veneno}

Todos os mamíferos são suscetíveis ao veneno botrópico (FOWLER, 1993), no entanto os animais domésticos diferem em suscetibilidade a esse veneno. As espécies mais sensíveis, em ordem decrescente; são as seguintes: eqüina, ovina, bovina, caprina, canina, suína e felina (BRAZIL, 1918; ARAÚJO; BELLUOMINI, 19601962; MÉNDEZ; RIET-CORREA, 1995). Grandes ani- 


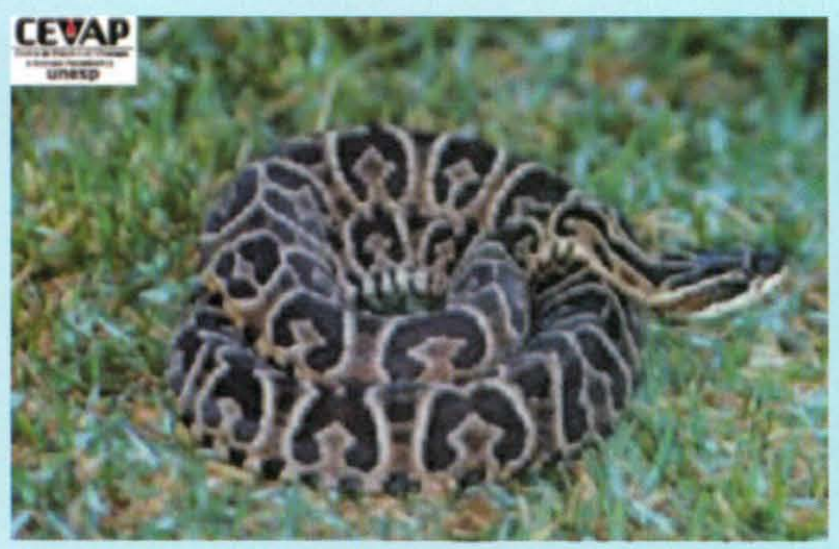

Figura 1. B. alternatus (urutu-cruzeiro).

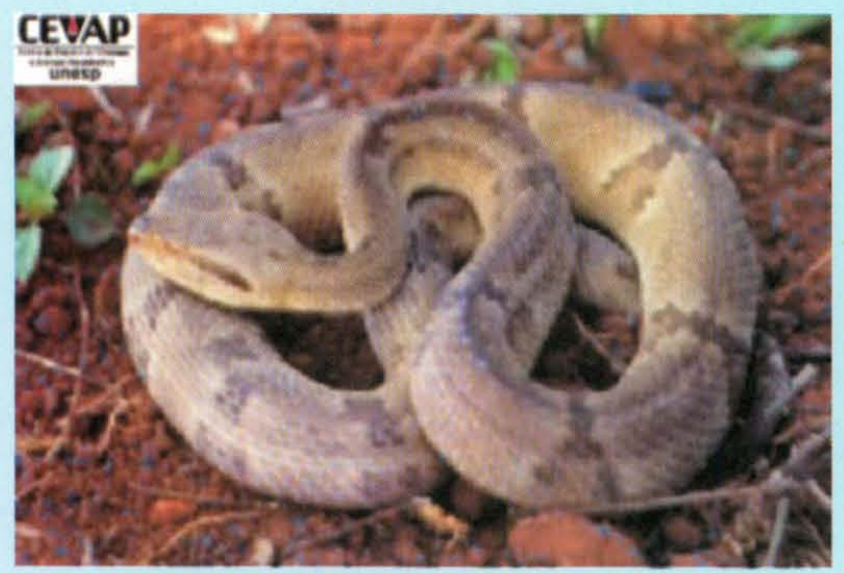

Figura 2. B. insularis (Jararaca ilhoa).

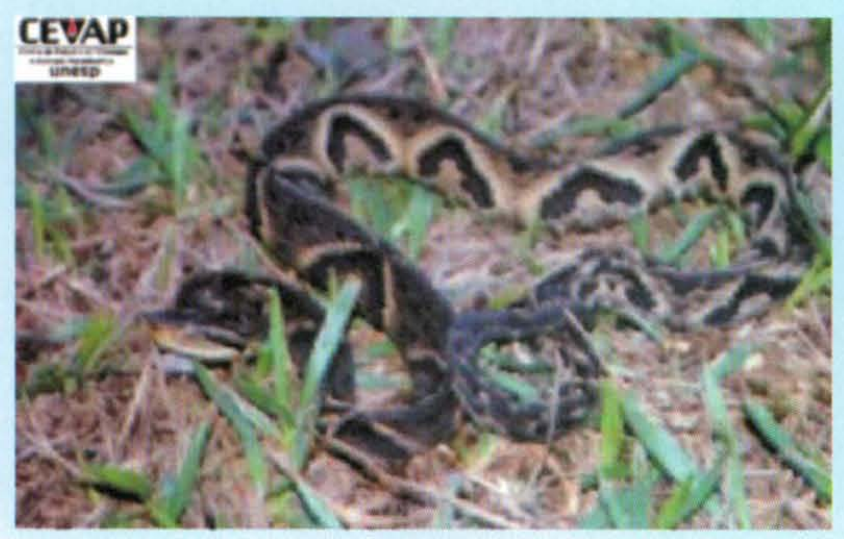

Figura 3. B. jararaca (Jararaca).

mais são mais resistentes que os pequenos porque é necessária a inoculação de uma maior quantidade de veneno para produzir-lhes a morte (MÉNDEZ; RIET-CORREA, 1995). Os suínos parecem apresentar maior resistência quando inoculados experimentalmente (ARAÚJO; BELLUOMINI, 1960-62). Em bovinos e ovinos os locais anatômicos mais afetados são aa região da cabeça

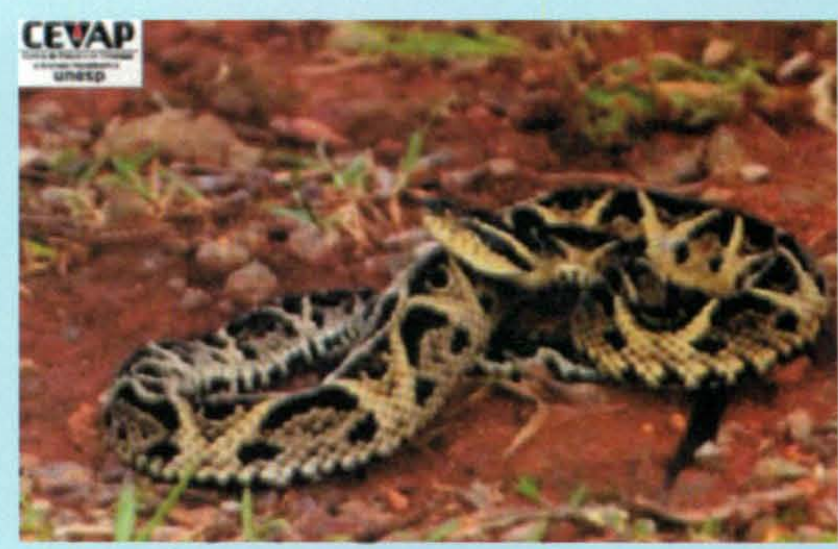

Figura 4. B. jararacussu (Jararacuçu).

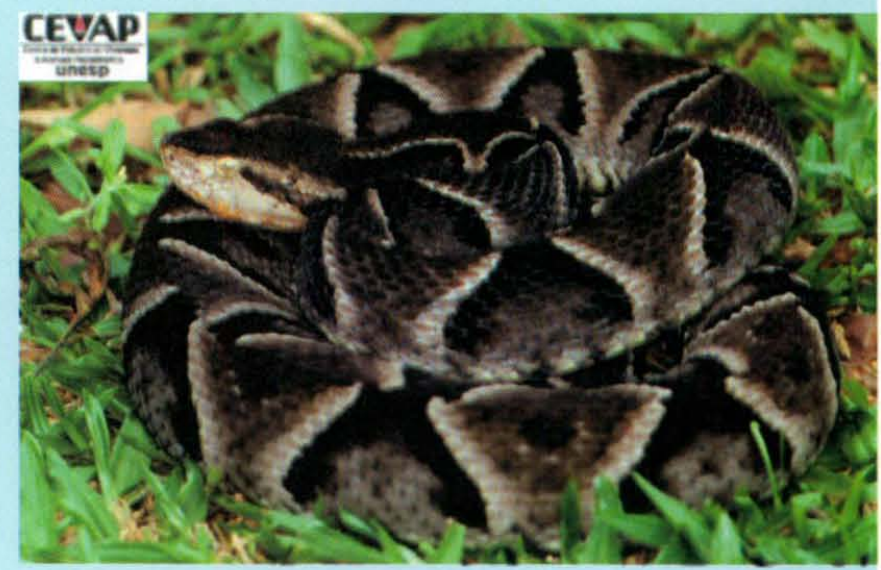

Figura 5. B. moojeni (Caissaca).

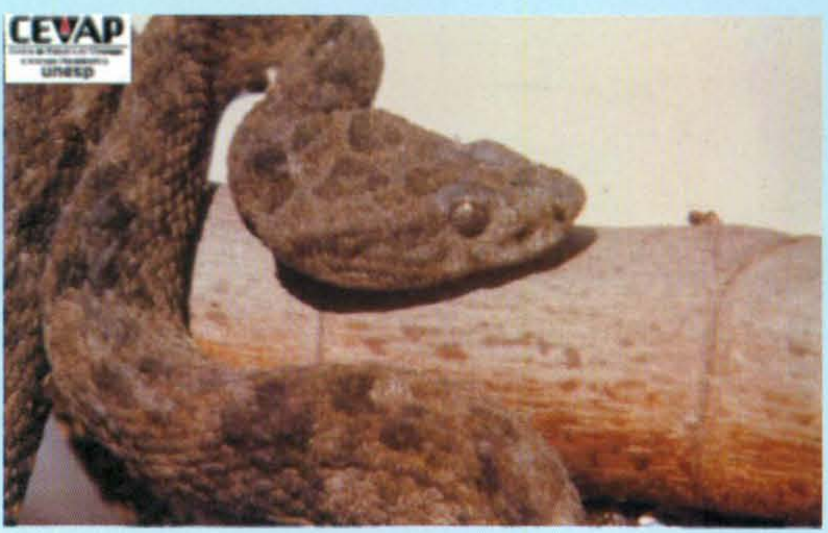

Figura 6. B. castelnaudi (Jararaca cinza). (Gentileza Dr. Helio Émerson Belluomini).

(focinho ou muflo), membros e úbere (BIONDO et al., 1993; MENDEZ; RIET-CORREA, 1995; SMITH, 1996). Isso se deve ao próprio comportamento alimentar dos ruminantes e ao fato de algumas das serpentes possuírem a capacidade de permanecer com um terço do corpo levantado e, no momento do bote, podem alcançar cerca de $0,4 \mathrm{~m}$ de altura (ROSENFELD, 1991). 


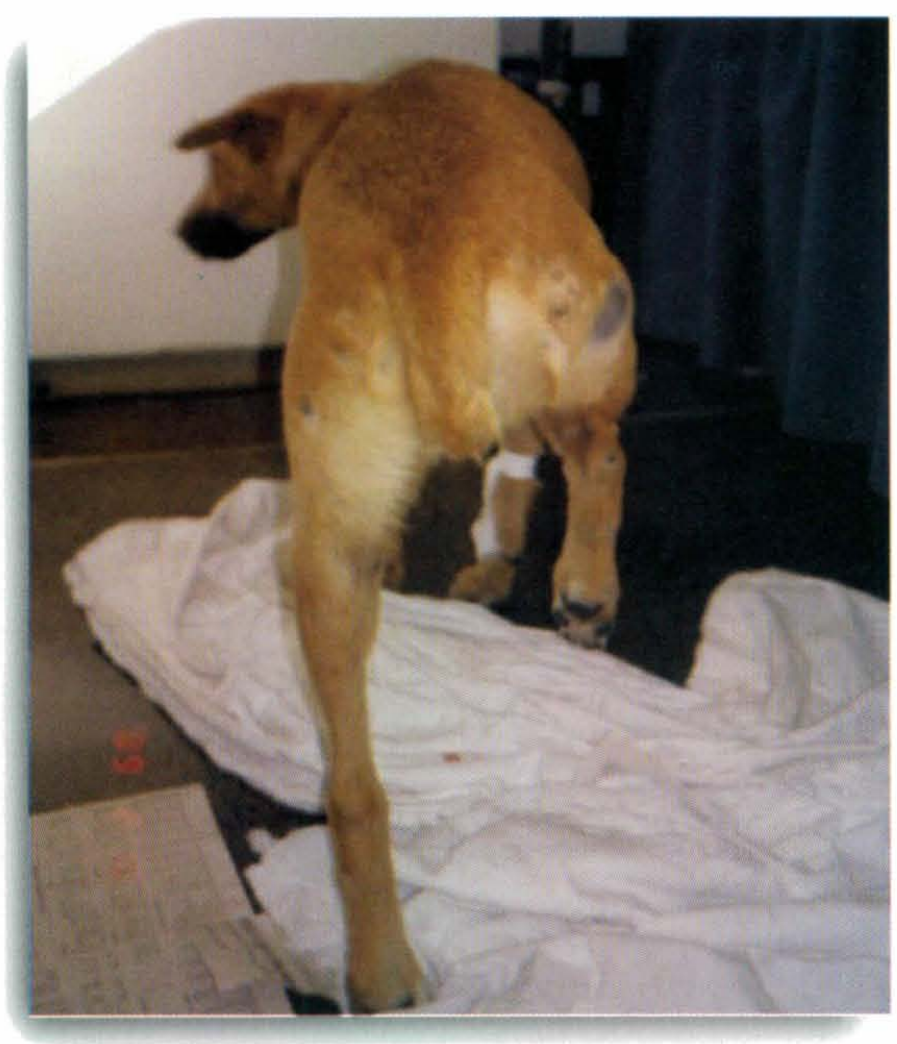

Figura 7. Animal apresentando claudicação do membro posterior direito após inoculação experimental com veneno botrópico.

Há uma espécie recém descoberta de jararaca, encontrada pelos biólogos na ilha de Alcatraz, litoral norte do Estado de São Paulo, popularmente chamada de jararaca-de-alcatrazes, espécie em perigo de extinção, em virtude dos treinos de bombardeios praticados pela Marinha do Brasil. A espécie deve ser batizada como Bothrops alcatraz, em homenagem à ilha onde foi encontrada (LIMA, 2001).

\section{Patogenia}

$\mathrm{O}$ veneno das serpentes do gênero Bothrops possui uma mistura de enzimas, peptídeos e proteínas de pequeno peso molecular que apresentam atividades químicas e biológicas específicas (MÉNDEZ, 1998). Cerca de 90 a $95 \%$ do peso seco do veneno consistem de proteínas, das quais algumas apresentam atividade proteolítica e contêm cálcio e zinco em suas moléculas, denominadas de metaloproteases (VARANDA; GIANINNI, 1994). A composição geral consiste de hialuronidase, responsável pela rápida absorção e dispersão entre os tecidos, de hemotoxinas e citolisinas que determinam infla- mação local, necrose e dano ao epitélio vascular, de fosfolipase A e estearase, que alteram a permeabilidade da membrana e liberam histamina e bradicinina (MÉNDEZ, 1998). A atividade da fosfolipase A está presente em todos os venenos botrópicos, exceto no da $B$. cotiara (ZINGALI et al., 1988).

O veneno botrópico possui ação necrosante, coagulante, vasculotóxica e nefrotóxica. A necrose é provocada pela ação citotóxica tecidual direta causada por enzimas proteolíticas que induzem a liberação de substâncias vasoativas, como a bradicinina e histamina causando intensa reação local com dor, edema, congestão, hemorragia e necrose (liponecrose e mionecrose) (BARRAVIERA; PEREIRA, 1991; KOUYOUMDJIAN et al., 1990; MÉNDEZ, 1998). A isquemia no local afetado, causada por importantes alterações na microcirculação e artérias intramusculares, contribui sobremaneira para a necrose (GUTIÉRREZ; LOMONTE, 1989).

A ação coagulante é decorrente da transformação do fibrinogênio diretamente em fibrina e da ativação do fator X e da ação da protrombina. A ativação da cascata de coagulação pode levar ao consumo de fibrinogênio e desencadear incoagulabilidade sangüínea. $\mathrm{O}$ animal pode, ainda, desenvolver coagulação intravascular disseminada (CID) com a formação de microcoágulos e comprometimento de outros órgãos (KOUYOUMDJIAN et al., 1990; MÉNDEZ, 1998).

A ação vasculotóxica sistêmica é devida às hemorragias que agem sobre os capilares, destruindo inicialmente a membrana basal e causam a lise das células endoteliais de capilares sangüíneos, provocando, posteriormente, a sua ruptura. As lesões podem ser locais e/ou sistêmicas, levando à hemorragia e ao edema, e podem

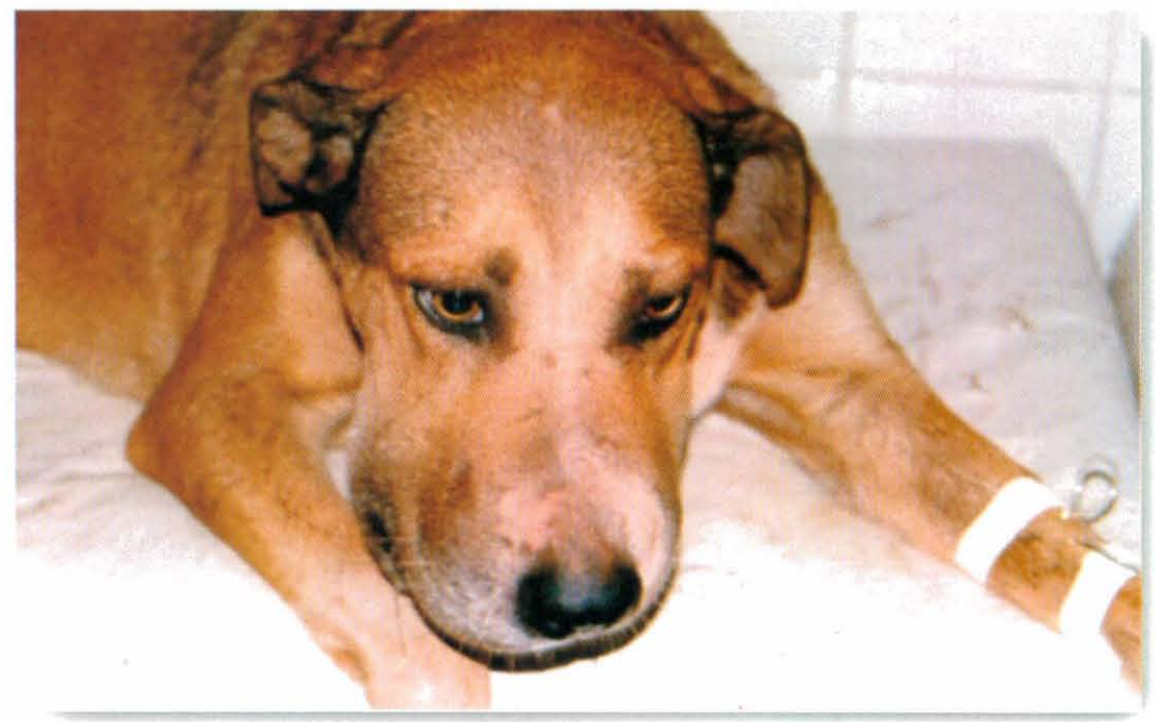

Figura 8. Cão picado por Bothrops sp no focinho, apresenta edema no local e apatia. 


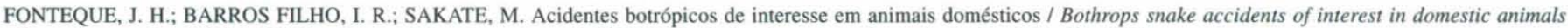
/ Rev. educ. contin. CRMV-SP/ Continuous Education Journal CRMV-SP, São Paulo, volume 4, fascículo 3, p. 102 - $111,2001$.

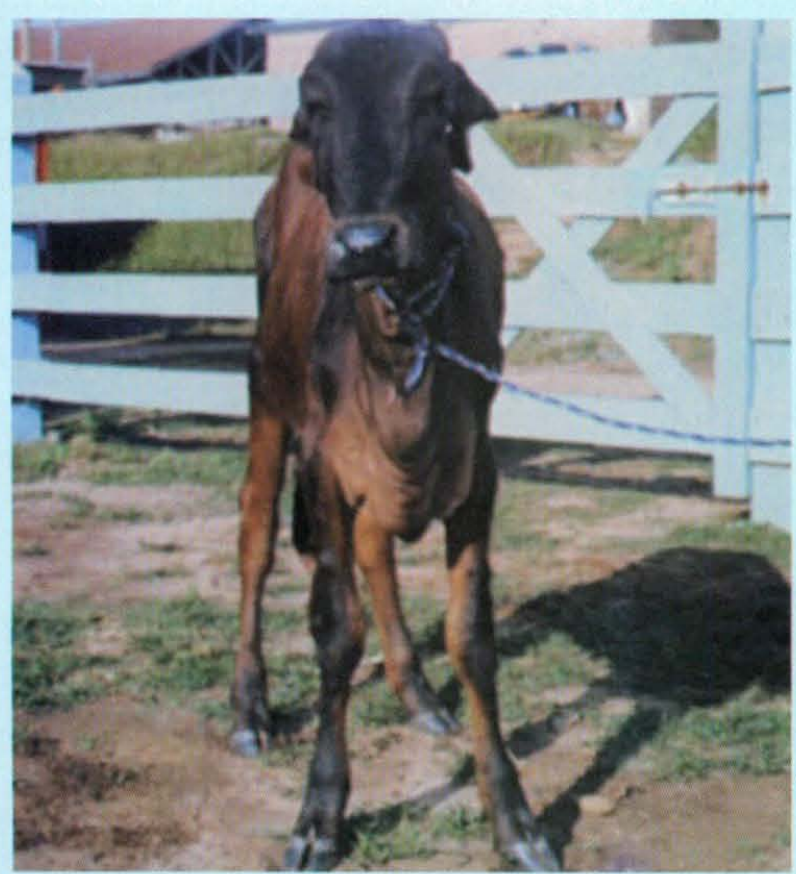

Figura 9. Bezerro apresentando edema de barbela.no local da picada.

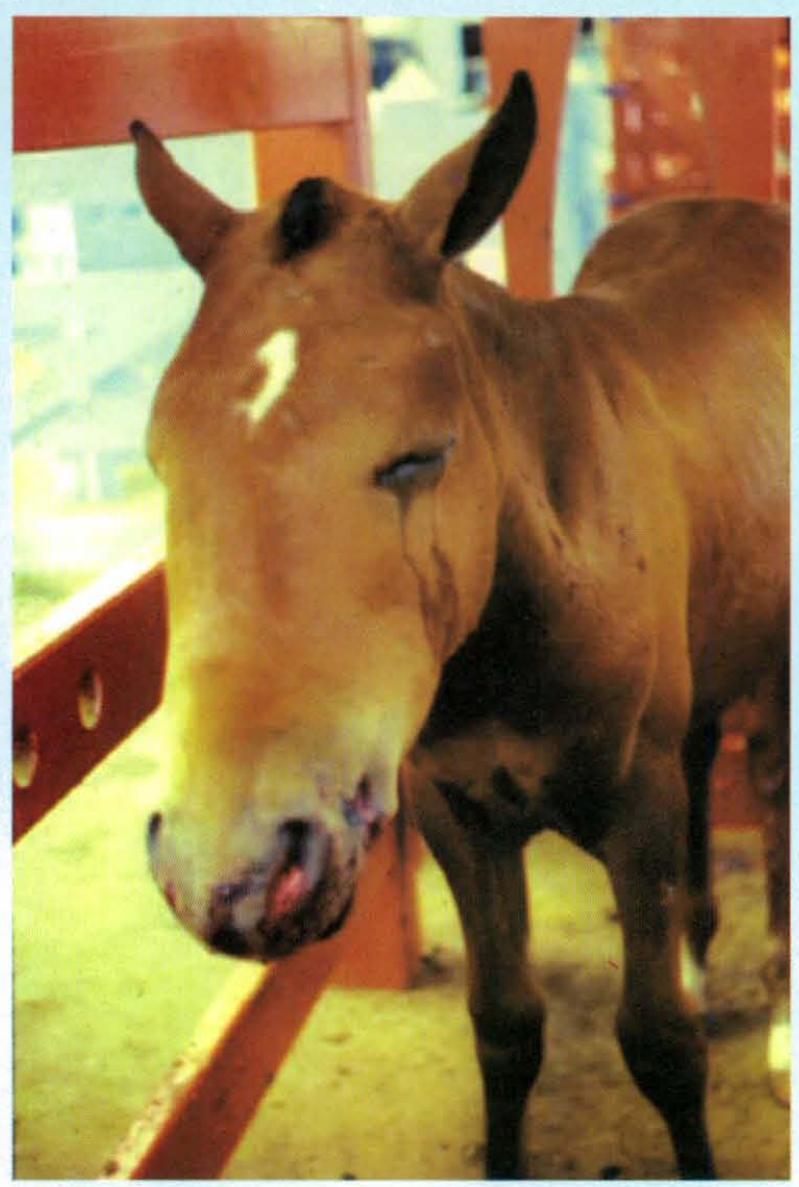

Figura 10. Eqüino vítima de acidente botrópico. Houve necessidade de traqueostomia e o animal foi a óbito no dia seguinte por hemorragia e necrose no local da picada. ocorrer em minutos após o acidente (BARRAVIERA; PEREIRA 1991; MÉNDEZ, 1998).

A nefrotoxicidade é devida à ação tóxica direta do veneno sobre os rins com lesão celular e indiretamente pelo choque hipovolêmico ou por meio de microcoágulos que provocam obstrução da microcirculação levando à isquemia (AMARAL et al., 1985; AMARAL et al., 1986).

\section{Sinais clínicos}

A gravidade do quadro clínico dependerá da sensibilidade do animal ao veneno, da quantidade de veneno inoculada, do local afetado, e do tempo decorrido o acidente (BERROCAL et al., 1998). Segundo SCHVARTSMAN (1985), a reação local é rápida, intensa e pode ser evidenciada duas horas após o acidente.

Na maioria dos animais, ocorrem prostração, inapetência, aumento das frequiências respiratórias e cardíacas e queda da produção leiteira (GRUNERT; GRUNERT, 1969; MÉNDEZ, 1998). Há uma reação local rápida e intensa com edema local e equimoses (SCHVARTSMAN, 1985). À palpação, na região da picada, nota-se uma tumefação de consistência pastosa com elevada sensibilidade dolorosa (GRUNERT; GRUNERT, 1969). Podem ser observados dois pontos de hemorragia correspondendo ao local de perfuração pelas presas, porém nem sempre esses são identificados (GUTIÉRREZ; LOMONTE, 1989; NOVAES et al., 1999 ). Em muitos animais, observa-se claudicação quando a picada se localiza no membro (MÉNDEZ, 1998) (Figura 7).

Quando a picada ocorre na cara dos animais, geralmente no focinho, a reação local pode provocar grave edema (MENDEZ; RIET-CORREA, 1995) (Figura 8), que pode atingir o maxilar inferior, o pescoço e a região torácica. No caso de obstrução das vias respiratórias superiores podem ocorrer dispnéia e insuficiência respiratória pelo edema de glote (GRUNERT; GRUNERT, 1969) e a traqueostomia passa a ser procedimento de emergência para assegurar a sobrevivência do animal (Figuras 9 e 10).

Em animais de grande porte com picadas no focinho, é comum a necessidade de passagem de sonda nasogástrica para proceder a alimentação, mas essa manipulação pode levar a hemorragias intensas, devidas às alterações na coagulação sangüínea provocadas pelo veneno botrópico.

Em bovinos, o grau máximo de edema é evidenciado em média 48 horas após a inoculação podendo permanecer por até 120 horas. As cobras do gênero B. jararaca, B. alternatus e B. moojeni provocam edemas 
FONTEQUE, J. H.; BARROS FILHO, I. R.; SAKATE, M. Acidentes botrópicos de interesse em animais domésticos / Bothrops snake accidents of interest in domestic animals / Rev. educ. contin. CRMV-SP / Continuous Education Journal CRMV-SP, São Paulo, volume 4, fascículo 3, p. 102 - 111, 2001.

mais intensos quando comparadaa à $B$. neuwiedii (NOVAES, 1999). SALIBA, em 1964, num experimento em coelhos, demonstrou que na área de necrose formaramse placas de fibrina, as quais, à medida que decorriam os dias, tornaram-se crostas secas e, ainda, a ocorrência de hemorragia abdominal (Figura 11).

\section{Seqüelas e complicações}

O local da picada pode ser contaminado por bactérias provenientes da flora bucal e do veneno presente nas glândulas das serpentes, bem como por substâncias aplicadas sobre o ferimento, incisões por instrumentos cortantes e pelo próprio meio ambiente (JORGE; RIBEIRO, 1997). Em aproximadamente $9 \%$ dos casos de envenenamentos em seres humanos ocorre a formação de abscessos, devido a presença dos seguintes agentes microbianos: Morganela morganii, Proteus rettgeri, Enterobacter spp e Escherichia coli, Enterococcus spp e Bacterioides spp. A M. morganii. Algumas enterobactérias podem ser isoladas do veneno e da boca de serpentes, que as inoculam no momento da picada (JORGE; RIBEIRO, 1997).

A mortalidade por acidente botrópico é baixa, porém seqüelas importantes podem limitar a capacidade física do animal, caso não seja realizado um tratamento adequado. Algumas complicações incluem a hemorragia, hipovolemia e, consequentemente, choque, que é a principal causa de morte. A perda de extremidades pode ocorrer por gangrena úmida ou seca, pela infecção bacteriana ou devida à isquemia e à necrose pela ação proteolítica do veneno (MÉNDEZ, 1998). No homem, essa letalidade é da ordem de 3,99\% dos casos (BARRAVIERA; PEREIRA, 1991). Na Veterinária, segundo SAKATE (2001-Comunicação pessoal), essa mortalidade também é baixa nos animais atendidos no Hospital Veterinário da Faculdade de Medicina Veterinária e Zootecnia UNESP, Botucatu, SP. Outra complicação a ser considerada é a contaminação local pelo Clostridium tetani, podendo levar ao desenvolvimento do tétano (GUIDOLIN et al., 1998).

\section{Patologia clínica}

Em seres humanos ocorrem leucocitose com neutrofilia, linfopenia, aumento do tempo de coagulação, proteínas $\mathrm{C}$ reativas e mucoproteínas, diminuição das proteínas totais, albumina e sedimentação de eri- trócitos, nos primeiros dias após o acidente. As citocinas estão aumentadas nos primeiros cinco dias após a inoculação (BARRAVIERA et al., 1995). Não há correlação entre a gravidade do edema local e anormalidade do tempo de coagulação (KOUYOUMDJIAN et al., 1990).

Em cães inoculados experimentalmente com veneno de $B$. jararaca, foi observada leucocitose com neutrofilia, linfopenia e monocitose. Porém, não foi evidenciada alteração do quadro eritrocitário (SANO-MARTINS et al., 1994). Segundo TAKAHIRA (1996), em um experimento que houve inoculação de veneno de $B$. jararaca em cães, observou-se a diminúição significativa de contagem total de plaquetas, hemácias, linfócitos, eosinófilos, megacariócitos, do volume globular, fibrinogênio, hemoglobina, proteína plasmática total, uréia, creatinina, proteínas séricas e albumina. Houve ainda, um aumento significativo da contagem total de leucócitos, neutrófilos segmentados e monócitos e dos níveis de produtos de degradação da fibrina, alanina aminotransferase, fosfatase alcalina e creatinoquinase.

O tempo de coagulação, de tromboplastina, de tromboplastina parcial ativada, protrombina e trombina estava significativamente aumentado em cães inoculados com veneno de serpentes do gênero Bothrops (TAKAHIRA, 1996) e no homem (EMANUEL, 1988).

MELO; SUARES-KURTZ (1987) relataram que o veneno botrópico tem a capacidade de elevar a atividade sérica da creatinoquinase em ratos, demonstrando a atividade lesiva do veneno ao tecido muscular.

\section{Achados de necropsia}

À necropsia, observa-se no local da picada, intenso edema sero-hemorrágico tornando-se em seguida

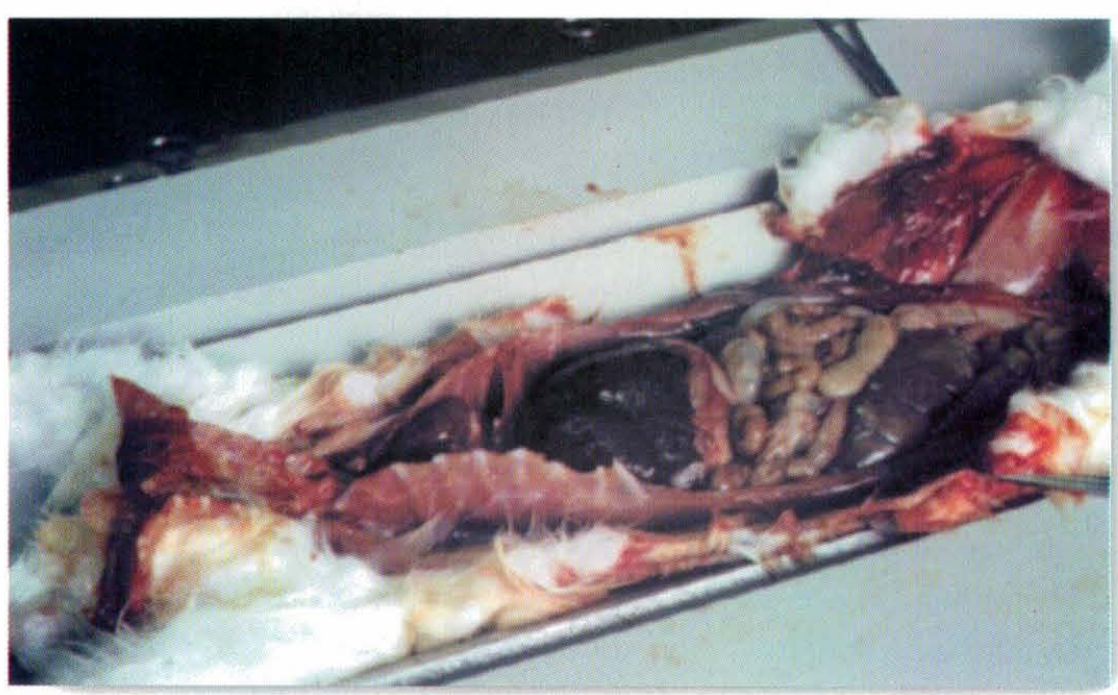

Figura 11. Hemorragia em cavidade abdominal de coelho (Gentileza Dr. Feres Saliba). 


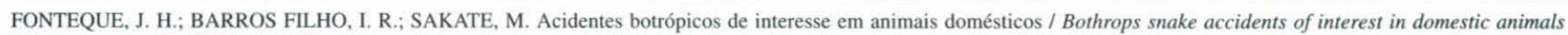
/ Rev. educ. contin. CRMV-SP/ Continuous Education Journal CRMV-SP, São Paulo, volume 4, fascículo 3, p. 102 - 111 , 2001.

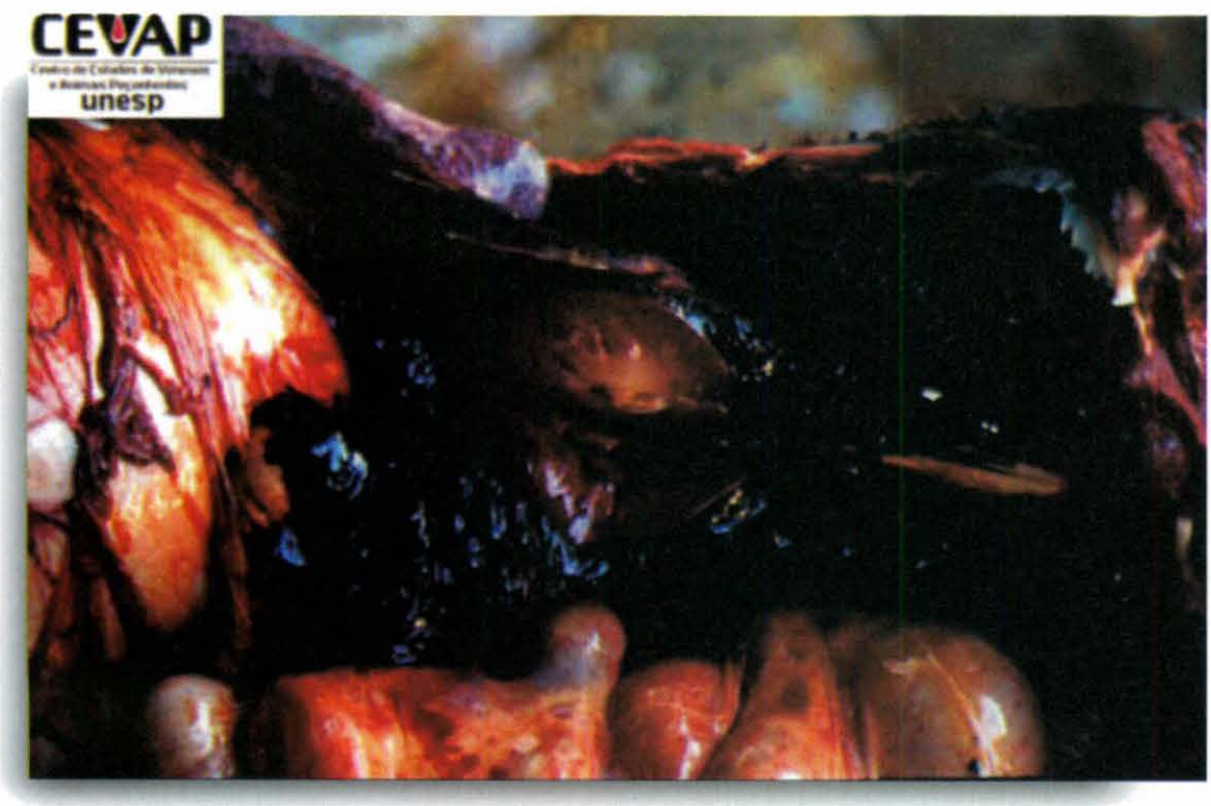

Figura 12. Hemorragia em cavidade abdominal.

espesso, gelatinoso e amarelado com a presença de sangue vermelho-escuro (Figura 12). Caso a lesão tenha alguns dias, observam-se tecido necrótico e secreção purulenta (Figura 13). Manifestações em outros órgãos são representados por enfisema pulmonar generalizado, áreas hemorrágicas nos epicárdio, miocárdio, endocárdio, pulmões, trato gastrointestinal, bexiga e rins (BERROCAL et al., 1998; MÉNDEZ, 1998).

BERROCAL et al. (1998) relataram equimoses no omento dos pré-estômagos e na parede ruminal, hepatomegalia e distensão da vesícula biliar com edema de parede e conteúdo escurecido .

Os linfonodos e as mucosas bucal, gastrointestinal e dos órgãos gênito-urinários apresentam-se hiperêmicos e hemorrágicos (GRUNERT; GRUNERT, 1969).

As lesões histopatológicas envolvem congestão e hemorragias graves na maioria dos órgãos, necrose tubular renal aguda e às vezes glomerulonefrite aguda, nefrite intersticial e necrose cortical renal (MÉNDEZ, 1998). Nos pulmões ocorre edema alveolar com hemorragia. No endocárdio, epicárdio e miocárdio, há edema e hemorragia com separação dos miócitos. A degeneração fibrinóide e o edema podem ser evidenciados nas paredes de várias artérias (BERROCAL et al., 1998).

\section{Diagnóstico}

Informações como a presença de serpentes na região, história de outros acidentes ofídicos e a evolução dos sinais clínicos são importantes dados obtidos durante a anamnese. Muitas vezes o diagnóstico do envenenamento é dificultado caso não se observe o momento da picada e o ofídio causador não seja capturado para que possa ser realizada a identificação do animal. Em animais de fazenda, diferente dos pequenos animais, geralmente, a observação da vítima é feita tardiamente em virtude do sistema de criação extensivo. Porém, por meio dos sinais clínicos, pode-se suspeitar do gênero envolvido e procederse o tratamento. A confirmação da suspeita clínica é realizada por meio de exames laboratoriais e pelo sucesso da terapia empregada (GRUNERT; GRUNERT, 1969; MÉNDEZ, 1998).

\section{Tratamento}

A eficiência do tratamento com o soro depende essencialmente da sua especificidade (ROSENFELD, 1991). Deve ser realizada mais rapidamente possível a administração de soro específico para o gênero Bothrops (soro antibotrópico) ou soro-polivalente(soro antiofídico que contenha soro antibotrópico), na dose que neutralize, no mínimo, $100 \mathrm{mg}$ do veneno botrópico. O soro deve ser aplicado lentamente por via intravenosa e, na impossibilidade, por via subcutânea ou intramuscular. Administrações adicionais de metade da dose inicial podem ser realizadas no caso de o sangue permanecer incoagulável 12 horas após o início do tratamento. O tamanho e o peso do animal não são considerados para o cálculo da quantidade de soro a ser aplicada. Assim, o volume a ser aplicado num bovino é o mesmo a ser aplicado no cão (BICUDO, 1994).

Em estudo experimental, no qual cães receberam soroterapia na dose de $2,5 \mathrm{ml}$ de soro anti-botrópico para cada $1,0 \mathrm{mg}$ de veneno após 12 horas da inoculação, demonstrou-se a eficácia da terapia para prevenir a morte dos animais e restabelecer as condições clínicas normais (TAKAHIRA, 1996). Deve-se salientar que, nesse caso, a dose do veneno inoculada era previamente conhecida, o que não acontece nas condições de acidentes.

Segundo NOVAES et al.(1999), uma terapia alternativa seria o uso de flunixin-meglumine associado à furosemida. Esses autores salientam que os antiinflamatórios não neutralizam o veneno, e, sim, agem apenas sobre o edema, inibindo a quimiotaxia celular, 


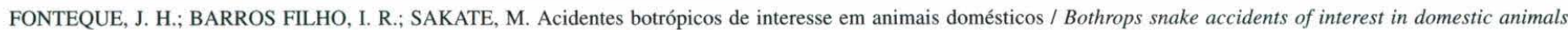
/ Rev. educ. contin. CRMV-SP / Continuous Education Journal CRMV-SP, São Paulo, volume 4, fascículo 3, p. 102 - 111, 2001.

diminui a lesão tecidual e faz com que haja a menor possibilidade de infecção bacteriana local. A utilização de anti-histamínico é contra-indicada pois o veneno provoca um processo que ultrapassa a fase histamino-dependente, requerendo medicamentos que atuem sobre os intermediadores como a prostaglandina.

É contra-indicada a colocação de torniquetes ou a realização de cortes no local da picada, pois pode aumentar a lesão ou causar hemorragias importantes devido à ação do veneno sobre a coagulação sangüínea.

Em casos em que a picada se localize na região da cabeça, podem ocorrer dificuldades respiratória e na ingestão de alimentos. Deve-se proceder à enfermagem com alimentação via sonda gástrica até que o animal se torne capaz de se alimentar voluntariamente. A traqueostomia é um procedimento emergencial de vital importância, principalmente nos eqüinos, que não possuem capacidade de respirar pela boca. Devese considerar que existe a possibilidade de hemorragias extensas no local do procedimento cirúrgico, devida à ação do veneno sobre a coagulação sangüínea, e o clínico deve estar ciente dos riscos e agir com bom senso.

\section{Reações à soroterapia}

A frequiência de reações à soroterapia (antiveneno) em humanos é considerada alta no Brasil com cerca de $67,5 \%$ de casos. Em animais domésticos segundo SAKATE, 1999 (comunicação pessoal), alguns casos de reações ao soro têm sido observados em cães e bovinos no Hospital Veterinário da Faculdade de Medicina Veterinária e Zootecnia UNESP, de Botucatu-SP. Nessas situações, deve-se interromper imediatamente a administração do antiveneno e realizar o protocolo de tratamento para choque, utilizando-se de fluidoterapia, corticóides, adrenalina, oxigenoterapia, de acordo com o quadro apresentado pelo animal.

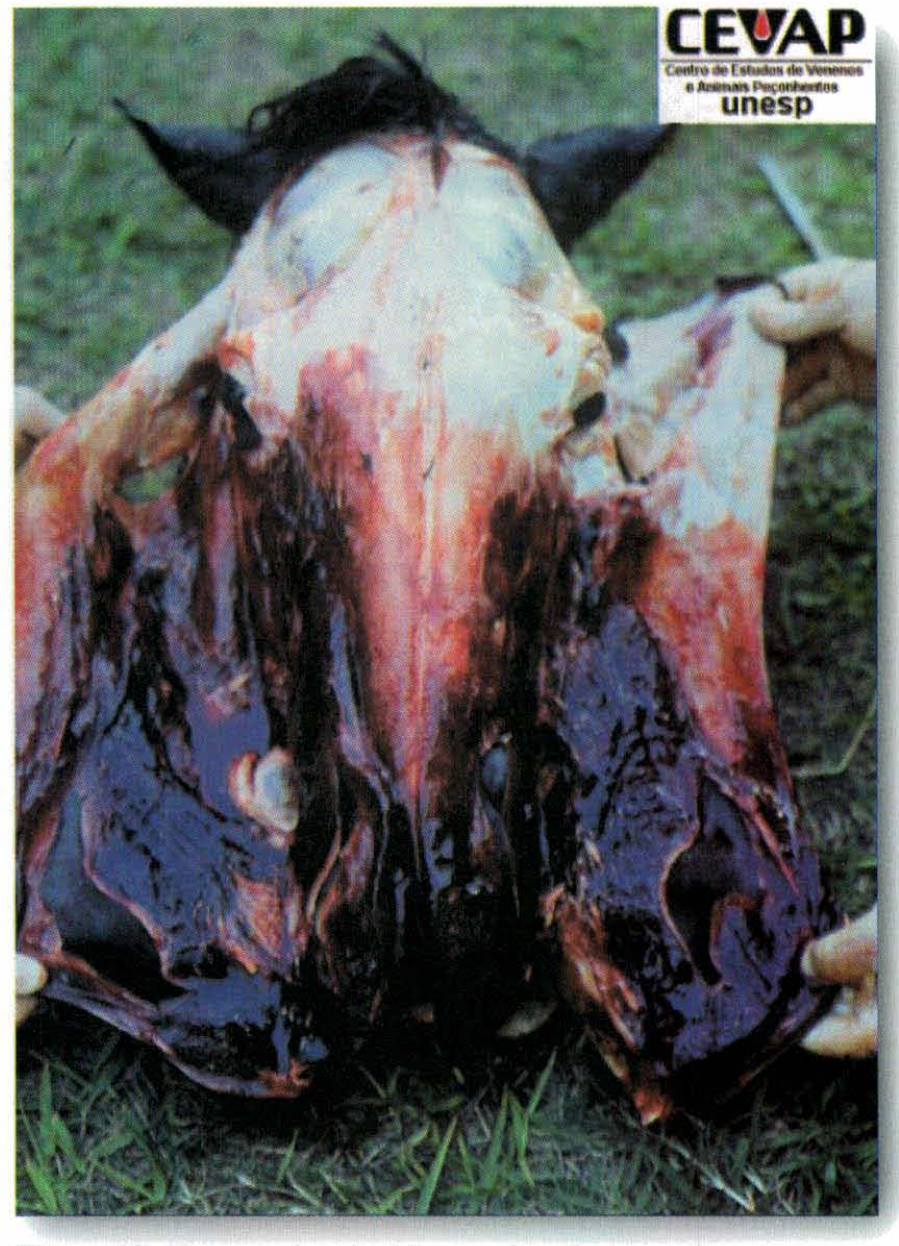

Figura 13. Hemorragia subcutânea na face de um equino.

\section{Conclusão}

Os acidentes botrópicos são importantes em Medicina Veterinária, pois podem desencadear graves reações locais e sistêmicas, necessitando de rapidez na elaboração do diagnóstico e na instituição do tratamento adequado, para diminuir e controlar os sinais e sintomas clínicos e evitar seqüelas que prejudiquem a vida futura do animal.

\section{SUMMARY}

The objective of this review is to present information about Bothrops envenomation in domestic animals, describing the major Bothrops species, animals sensitivity to venom, pathogenicity, clinical signs, sequelae and complications, laboratory and necropsy findings, diagnosis, treatment and reactions to serum therapy.

Key words: Bothrops, venomous animals, Bothrops accidents, domestic animals. 


\section{AGRADECIMENTOS}

Ao Centro de Estudos de Venenos e Animais Peçonhentos (CEVAP), ao Prof. Dr. Hélio Émerson Belluomini e ao Prof. Dr. Feres Saliba pela autorização da utilização das fotos neste trabalho. À bibliotecária Rosemary Cristina da Silva, pela correção das referências bibliográficas.

\section{REFERÊNCIAS}

1. ALVES, A. L. et al. Cartilha de ofidismo (Cobral). Brasília: Ministério da Saúde, 1989. 32 p.

2. AMARAL, A. Serpentes do Brasil. Iconografia colorida. 2. ed. Melhoramento: São Paulo, 1978. 246 p.

3. AMARAL, C. F. S. et al. Insuficiência renal aguda secundária a acidentes ofídicos botrópicos e crotálicos. Análise de 63 casos. Revista do Instituto de Medicina Tropical de São Paulo, v. 28 , n. 4 , p. $220-227,1986$.

4. AMARAL, C. F. et at. Renal cortical necrosis following Bothrops jararaca and Bothrops jararacussu snake bite. Toxicon, v. 23 , n. 6 , p. $877-885,1985$.

5. ARAUJO, P.; BELLUOMINI, H. E. Toxicidade de venenos ofídicos, I- Sensibilidade específica de animais domésticos e de laboratório. Memórias do Instituto Butantan, v. 30, p. 133142, 1960-1962.

6. BARRAVIERA, B.; BONJORNO, J. R.; ARAKAKI, D. A retrospective study of 40 victims of Crotalus snake bites. Analysis of the hepatic necrosis observed in one pacient. Revista da Sociedade Brasileira de Medicina Tropical, v. 22, n. 1, p. 512, 1989.

7. BARRAVIERA, B. et al. Acute-phase reactions including cytokines in patients bitten by Bothrops and Crotalus snakes in Brazil. Journal Venomous Animals Toxins, v. 1, p. 11-22, 1995.

8. BARRAVIERA, B.; PEREIRA, P. C. M. Acidentes por serpentes dos gêneros Bothrops, Lachesis e Micrurus. Arquivos Brasileiro de Medicina, v. 65, p. 345-355, 1991.

9. BELLUOMINI, H. E. Conhecimento sobre as serpentes brasileiras e medidas de prevenção de acidentes. Revista Brasileira de Saúde Ocupacional, v. 12, n. 45, p. 82-96, 1984.

10. BERROCAL, A.; GUTIERREZ, J. M.; ESTRADA, R. Snake envenomation in bovine. Large Animal Practice, v. 19, n. 4, p. 26-27, 1998.

11. BICUDO, P. L. Acidentes ofídicos em Medicina Veterinária. In: BARRAVIERA, B. Venenos animais: uma visão integrada. Rio Janeiro: Científica, 1994. cap. 29, p. 375-387.

12. BIONDO, A. W.; BICUDO, P. L.; KOHAYAGAWA, A. Acidentes ofídicos em Medicina Veterinária - revisão de 1260 notificações do Instituto Butantan. In: Jornada Científica da Asso- ciação dos Docentes, 28, 1993, Botucatu, Anais... Botucatu: UNESP, 1993 p. 159.

13. BRAZIL, V. Contribuição ao estudo do veneno ophidico. Colletanea de Trabalhos 1901-1917. Instituto Butantan, São Paulo. Tyo do Diario Oficial, São Paulo, p. 1-30, 1918.

14. BRAZIL, V.; RANGEL PESTANA, B. Nova contribuição ao estudo do envenenamento ophidico. Colletanea de Trabalhos 1901-1917, Instituto Butantan, São Paulo. Tyo Diario Oficial, São Paulo, p. 149-193, 1918.

15. BÜCHERL, W. Acúleos que matam. São Paulo: Empresa Gráfica da Revista dos Tribunais, 1979. 153 p.

16. CAMPBELL, J. A.; LAMAR, W. The venomous reptiles of latin America. Ithaca: Cornell University Press, 1989. 425 p.

17. CEVAP (Centro de Estudos de Venenos e Animais Peçonhentos). Emergências Veterinárias. Botucatu, UNESP, 2001. Disponível em: <http://www.cevap.org.br> Acesso em: 18 de abr. 2001.

18. DAL PAI, V.; SANTO NETO, H. Ação dos venenos ofídicos sobre tecidos animais. In: BARRAVIERA, B. Venenos animais: uma visão integrada. Rio de Janeiro: Ed. Public. Científicas, 1994. cap. 8, p. 97-105.

19. DOURADO, H. V.; BUHRNHEIM, P. F.; SOUZA, I. S. Ofidismo no Amazonas. Apresentado ao Congresso Brasileiro da Sociedade Brasileira Medicina Tropical. Revista Brasileira de Medicina Tropical, v. 21, p. 119, 1988. Suplemento 1.

20. EMANUEL, A. Estudo da coagulação em pacientes com acidente ofídico. Congresso Brasileiro da Sociedade Brasileira de Medicina Tropical. Revista Brasileira de Medicina Tropical, v. 21, p. 115, 1988. Suplemento 1.

21. FONSECA, F. Animais peçonhentos. São Paulo: Instituto Butantan, 1949. $376 \mathrm{p}$.

22. FOWLER, M. E. Veterinary zootocoxicology. Boca Raton: CRB Press, 1993. cap.16, p. 175-85.

23. FRANCISCO, C. R. Répteis do Brasil: manutenção em cativeiro. São Paulo: Ed. Amaro, 1997. 208 p.

24. GRUNERT, E.; GRUNERT, D. Observaciones de lesiones por mordedura de serpiente "Bothrops" en los bóvidos y caballos en Rio Grande do Sul/Brasil. Notícias Médico Veterinárias, cad 3, p. 213-227, 1969. 


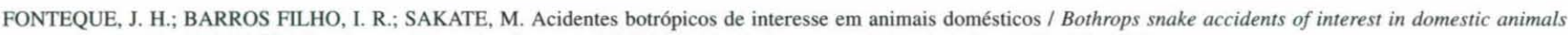
/ Rev. educ. contin. CRMV-SP / Continuous Education Journal CRMV-SP, São Paulo, volume 4, fascículo 3, p. 102 - $111,2001$.

25. GUIDOLIN, R.; STEPHANO, M. A.; MORAIS, J. F. et al. Production of an effective anti Bothrops - Tetanus mixed hyperimmune serum of equine origin, Journal Venomous Animals Toxins, v. 4, p. 70-78, 1998.

26. GUTIÉRREZ, J. M.; LOMONTE, B. Local tissue damage induced by bothrops snake venom. A review. Memórias do Instituto Butantan. v. 51, n. 4, p. 211-223, 1989.

27. HOGE, A. R.; BELLUOMINI, H. E. Notas sobre Bothrops fonsecai Hoge e Belluomini, Bothrops alternatus Duméril, Bibron et Duméril e Bothrops cotiara Gomes. Memórias do Instituto Butantan, v. 30, p. 97-102, 1960-62.

28. HOGE, A. R.; ROMANO-HOGE, S. A. R. W. L. Sinopse das serpentes peçonhentas no Brasil. Memórias do Instituto Butantan, v. 42-43, p. 373-396, 1978-1979.

29. JORGE, M. T.; RIBEIRO, L. A. Infections in the bite site after envenoming by snakes of the Bothrops genus. Journal Venomous Animals Toxins, v. 3, n. 2, p. 264-272, 1997.

30. KAMIGUTI, A. S. et al. The role of venom haemorrhagin in spontaneous bleeding in Bothrops jaracaca envenoming, Thromb. Haemost, v. 67, n. 4, p. 484-488, 1992.

31. KOUYOUMDJIAN, J. A.; POLIZELli, C.; LOBO, S. M. A. et al. Acidentes ofídicos causados por Bothrops moojeni na região de São José do Rio Preto, São Paulo. Arquivos Brasileiro de Medicina, v. 64, p. 167-171, 1990.

32. LIMA, A. Ilha de São Paulo tem nova espécie de cobra. Folha de São Paulo, São Paulo, 4 março de 2001. Ciência, Zoologia, p. A19.

33. MELO, P. A.; SUAREZ-KURZ. Interaction of Bothrops venoms and antivenin on release of creatine kinase from skeletal muscle. Brasilian Journal of Medical Biologycal Research, v. 20 , n. 6 , p. $821-824,1987$.

34. MÉNDEZ, M. C.; RIET-CORREA, F. Snakebite in Sheep. Vet Hum Toxicol, v. 37, n. 1, p. 62-63, 1995.

35. MÉNDEZ, M. C. Envenenamento Botrópico. In. RIET-CORREA, F.; SCHILD, A. L.; MÉNDEZ, M. C. Doenças de ruminantes e eqüinos. Pelotas: Ed. Grafica Universitária - UFPel, 1998, p. 451-458.

36. MILIER, R. A.; TU, A. T. Factors in snake venoms that increase capillary permeability. J. Pharm. Pharmacol., v. 41, p. 792-794, 1989.

37. NAHAS, L.; KAMIGUTI, A. S.; BARROS, M. A. R. Trombin-like and factor X-activator components of Bothrops snake venoms. Thromb. Haemost, v. 41, p. 314-328, 1979.

38. NOVAES, A. P. N. et al. Envenamento botrópico em bovinos: tratamento opcional. Veterinary News, v. 6, p. 8-11, 1999.
39. QUEIROZ, L. S. et al. Pathological changes in muscle caused by haemorrhagic and proteolytic factor from Bothrops jararaca snake venom. Toxicon, v. 23, n. 2, p. 341-345, 1985.

40. RIBEIRO, L. A. Estudo epidemiológico de acidentes por serpentes peçonhentas no Estado de São Paulo atendidos no Hospital Vital Brasil, 1988. São Paulo, 1991.104 f. Dissertação (Mestrado) - Faculdade de Saúde Pública, Universidade de São Paulo, São Paulo.

41. ROSENFELD, G. Acidentes por animais peçonhentos: serpentes, aranhas,escorpiões. In: VERONESI, R. Doenças infeciosas e parasitárias. 8. ed. Rio de Janeiro: Guanabara Koogan, 1991. p. 951-962.

42. SALIBA, F. Estudo anatomopatológico da evolução da necrose produzida experimentalmente por veneno de Bothrops jarara$c a$. Influência de substâncias órgano-heparinóides. Memórias do Instituto Butantan, v. 31, p. 191-200, 1964.

43. SANO-MARTINS, I. S. et al. Realiability of simple 20 minute whole blood clotting test (WBCT 20) as an indicator of low plasma fibrinogen concentration in patients envenomed by bothrops snakes. Toxicon, v. 32, n. 9, p. 1045-1050, 1994.

44. SCHVARTSMAN, S. Animais venenosos e animais peçonhentos. In: SCHVARTSMAN, S. Intoxicações agudas. 3. ed. São Paulo: Savier, p. 375-426, 1985.

45. SGARBI, L. P. S. et al. Human envenomations due to snakebites in Marilia, State of São Paulo, Brazil. A retrospective epidemiological study. Journal Venomous Animals Toxins, v. 1, n. 2, p. 70-78, 1995.

46. SMITH, B. P. Large animal internal medicine. 2. ed. Mosby: St Louis. 1996. 2040 p.

47. SORENSEN, B. Animais peçonhentos. São Paulo: Atheneu, 1990.

48. TAKAHIRA, R. Alterações hemáticas, hematológicas e bioquímicas de cães no envenenamento experimental por Bothrops jararaca (wiedi, 1824) e Bothrops newiedii Wangler, 1824. 1996. Dissertação (Mestrado) - Faculdade de Medicina Veterinária e Zootecnia, Universidade Estadual Paulista, Botucatu-SP.

49. VARANDA, E. A.; GIANINNI, M. J. S. M. Bioquímica de venenos de serpentes. In: BARRAVIERA, B. Venenos animais: uma visão integrada. Rio de Janeiro: Public. Científicas, 1994. cap. 14 , p. $205-23$.

50. ZINGALI, R. B.; FRANCISCHETTI, I. M.; CARLINI, C. R. et al. Biochemical and pharmacological screening of snake (Bothrops) venoms. Characterization of components acting on blood coagulation and platelet aggregation. Brazilian Journal Medical Biologycal Research, v. 21, n.4, p. 763-765, 1988. 